\title{
Laboreal
}

Volume $10 \mathrm{~N}^{\circ} 1$ | 2014

Análise ergonómica do trabalho e formação

\section{Constrangimentos organizacionais, distorção da comunicação e sofrimento ético : o caso dos centros de atendimento telefónico}

Restricciones organizativas, distorsión de la comunicación y sufrimiento ético: el caso de los centros de atención telefónica

Contraintes organisationnelles, distorsion de la communication et souffrance éthique : le cas des centres d'appels téléphoniques

Organizational constraints, distorted communication and ethical suffering: the case of call centers

\section{Duarte Rolo}

\section{OpenEdition}

Journals

\section{Edição electrónica}

URL: http://journals.openedition.org/laboreal/5409

DOI: 10.4000/laboreal.5409

ISSN: 1646-5237

\section{Editora}

Universidade do Porto

\section{Refêrencia eletrónica}

Duarte Rolo, « Constrangimentos organizacionais, distorção da comunicação e sofrimento ético : o caso dos centros de atendimento telefónico », Laboreal [Online], Volume 10 NN$^{0} 1$ | 2014, posto online no dia 01 julho 2014, consultado o 24 setembro 2020. URL : http://journals.openedition.org/laboreal/ 5409 ; DOI : https://doi.org/10.4000/laboreal.5409

Este documento foi criado de forma automática no dia 24 setembro 2020.

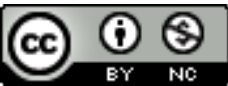

Laboreal está licenciado com uma Licença Creative Commons - Atribuição-NãoComercial 4.0 Internacional. 


\title{
Constrangimentos organizacionais, distorção da comunicação e sofrimento ético : o caso dos centros de atendimento telefónico
}

\author{
Restricciones organizativas, distorsión de la comunicación y sufrimiento ético: el \\ caso de los centros de atención telefónica \\ Contraintes organisationnelles, distorsion de la communication et souffrance \\ éthique : le cas des centres d'appels téléphoniques \\ Organizational constraints, distorted communication and ethical suffering: the \\ case of call centers
}

\section{Duarte Rolo}

\section{REFERÊNCIA}

Rolo, D. (2013). Contraintes organisationnelles, distorsion de la communication et souffrance éthique. Thèse de doctorat, Conservatoire National des Arts et Métiers, Paris.

1 A tese de doutoramento aqui apresentada teve por ponto de partida uma interrogação sobre o impacto psicológico de modos de organização do trabalho específicos, nomeadamente um conjunto de constrangimentos que instigam o uso da mentira, tornando-a num elemento central da atividade dos operadores. A descrição clínica de elementos relativos aos modos de organização do trabalho e da forma como estes são vivenciados pelos operadores constituiu um dos objetivos principais da tese. Nesse âmbito, levamos a cabo um estudo de caso num setor profissional específico: as centrais de atendimento telefónico ou call-centers. A recolha de material empírico foi feita de 
acordo com os princípios metodológicos da psicodinâmica do trabalho, referencial teórico que sustenta as discussões levadas a cabo ao longo da tese.

\section{Abordar o trabalho na perspetiva da psicodinâmica}

2 Herdeira dos estudos pioneiros da psicopatologia do trabalho e da ergonomia da atividade (Wisner, 1995), a psicodinâmica do trabalho dedica-se atualmente à análise e compreensão dos processos intersubjetivos gerados pela experiência do trabalho. De entre as diferentes abordagens do trabalho existentes atualmente, a psicodinâmica do trabalho confere um papel central à interação entre o sujeito e a sua atividade concreta para tentar apreender o aparecimento de novas formas de sofrimento no trabalho, pois o confronto entre o homem e o real do trabalho - ou seja, tudo aquilo que resiste ao contrôlo, ao domínio e à mestria do saber técnico ou científico - implica invariavelmente uma forma de desestabilização. Por conseguinte, o confronto com o real traduz-se sempre, em primeiro lugar, numa experiência desagradável. Isto porque o real se revela sob a forma do acidente ou da avaria, impondo a qualquer indivíduo um fracasso. Logo, o confronto com o real é antes de mais afetivo. A esta experiência afetiva a psicodinâmica escolheu dar o nome de sofrimento. $O$ sofrimento não é apenas uma consequência negativa do trabalho. Pelo contrário, é aquilo que conduz o trabalhador a procurar uma solução que lhe permitirá ultrapassar o próprio sofrimento que o persegue. Assim sendo, este sofrimento não significa forçosamente uma vivência patológica. Mediante certas condições, o dito sofrimento pode revelar ser um motor para a criatividade.

3 Tendo em conta estes elementos, a compreensão da vivência subjetiva dos agentes em psicodinâmica do trabalho focaliza-se nas manifestações de sofrimento no trabalho. Os métodos de investigação concentram-se, portanto, na dimensão propriamente subjetiva do trabalho, recolhida através do comentário feito pelos sujeitos relativamente à sua própria atividade. Sendo assim, nesta área de estudo os instrumentos de recolha de dados são invariavelmente qualitativos.

No nosso caso, foram utilizados três métodos de acesso ao trabalho real dos operadores em centros de atendimento telefónico:

- em primeiro lugar, ainda numa fase exploratória, desenvolvemos uma série de entrevistas individuais não diretivas com trabalhadores de call-centers;

- seguiu-se um período de observação participante enquanto teleoperador no seio de uma plataforma de atendimento;

- por último, conduzimos um inquérito coletivo nos moldes da psicodinâmica do trabalho (Ganem, 2011)[1].

\section{0 trabalho nos centros de atendimento telefónico e a mentira prescrita}

5 Os elementos recolhidos junto dos teleoperadores revelam que a mentira se tornou num aspeto central da sua atividade. Por mentira devemos entender qualquer ato em que um sujeito enuncie como sendo verdadeiro aquilo que toma todavia por falso. Dito de outra forma, mentir consiste em comunicar intencionalmente a outrém uma visão da realidade diferente daquela que consideramos verdadeira. No caso estudado, a 
mentira sob prescrição resulta de uma combinação de fatores organizacionais que levam os operadores a adotar a mentira como modo operacional. De uma forma geral, não existe uma prescrição explícita nem uma ordem direta para mentir. No entanto, os teleoperadores estão cientes de que os objetivos que lhes são impostos não podem ser atingidos sem mentir (as metas de venda definidas são impossíveis de alcançar sem mentir aos clientes, por exemplo). Consequentemente, embora não faça explicitamente parte da tarefa, a mentira passa a constituir uma dimensão fundamental da atividade.

6 Na verdade, o inquérito conduzido revela que a mentira serve, na grande maioria dos casos, como alavanca comercial. A sua utilização quotidiana reforça um argumentário cujo objetivo é o aumento das vendas a qualquer custo. Mesmo que isso implique enganar e ludibriar os clientes. Tais práticas não são, porém, inofensivas. Muitos trabalhadores mostram-se incomodados com este tipo de imposição que contradiz os seus princípios. $O$ facto de a mentira se ter infiltrado na atividade pode tornar-se problemático do ponto de vista da saúde mental, pois nem sempre é possível conciliar este tipo de prescrição com uma ética profissional que respeite os valores de um trabalho de prestação de serviços. De facto, esta contradição nem sempre é fácil de suportar. O sofrimento sentido pelos trabalhadores nestas circunstâncias está intimamente relacionado com o conflito que se instala entre os seus próprios valores e os valores subjacentes às práticas prescritas pela organização do trabalho.

\section{Conflito de valores e sofrimento ético}

7 Com efeito, estas imposições implicam por vezes a renúncia a um conjunto de valores que até à data tinham pautado a conduta profissional de grande parte dos teleoperadores. Levar a cabo ações ou executar ordens que, no final de contas, estes desaprovam, pode gerar uma forma de sofrimento específico que a psicodinâmica do trabalho apelidou de "sofrimento ético" (Dejours, 1998). O sofrimento ético surge quando o sujeito chega ao ponto de executar ordens com as quais não concorda. Dispôrse a servir um sistema que o próprio agente acaba por condenar dá origem a um conflito entre aquilo que o sujeito sabe que não deve aceitar mas que ainda assim faz. Ao contradizerem os seus valores, os trabalhadores correm o risco de perder a consideração que têm por si mesmos.

Porém, a traição de convicções ou ideais não origina forçosamente um sofrimento moral ou um sentimento de culpabilidade e é ainda menos certo que constitua sistematicamente uma causa de aparecimento de doenças ou de distúrbios psicológicos. Diversos estudos em clínica do trabalho demonstram efetivamente que o «trabalho sujo» (Hughes, 2010) é compatível com a realização pessoal. Sendo assim, como podemos explicar que uma parte dos trabalhadores entrevistados desenvolva sintomas relacionados com o conflito laboral que enfrentam, enquanto outros não dão sinais significativos de sofrimento? É impossível responder de forma satisfatória a esta questão sem recorrermos a uma das descobertas fundamentais da psicodinâmica do trabalho, designadamente as estratégias de defesa contra o sofrimento no trabalho. 


\section{Um conjunto de estratégias de defesa peculiares}

9 Os primeiros inquéritos em psicodinâmica do trabalho demonstraram que os trabalhadores desenvolvem estratégias de defesa que lhes permitem suportar os aspetos mais penosos da sua atividade (Dejours, 1980). Para satisfazerem as prescrições e corresponderem às expectativas da organização sem adoecerem, os trabalhadores utilizam estratégias de defesa contra o sofrimento, tais como o individualismo, a negação do perigo ou a hiperatividade.

10 Podemos definir estas estratégias como mecanismos através dos quais os trabalhadores buscam modificar, transformar e minimizar a perceção da realidade que os faz sofrer. Estas estratégias visam uma anulação simbólica dos perigos reais, concretamente relacionados com as condições de trabalho. São comportamentos intencionais, podem ser individuais ou coletivos (nesse caso são sustentados pelo consenso de um grupo específico de trabalhadores e têm uma função essencial para a constituição dos coletivos e das regras de trabalho), operam num plano simbólico e têm um efeito considerável sobre os afetos, ideias e comportamentos dos trabalhadores. Todas elas têm um impacto sobre a perceção da realidade e sobre a cognição dos sujeitos: as estratégias defensivas alteram os modos de pensar e de expressão. São estas estratégias de defesa que permitem à grande maioria dos trabalhadores manterem-se «normais» ou seja, evitarem a descompensação psicopatológica.

11 No caso do grupo profissional estudado, as ditas estratégias assumem diferentes formas. Encontramos, por um lado, estratégias de defesa individuais, tais como o ativismo, isto é, uma auto-aceleração solicitada e mantida pelos trabalhadores. 0 ativismo permite uma "anestesia" parcial do pensamento, graças a uma solicitação extrema do comportamento e da motricidade. $O$ atendimento frenético de telefonemas e uma entrega sem limites aos objetivos de produção permitem a alguns teleoperadores sonegarem os eventuais conflitos éticos. Manter uma azáfama comportamental serve precisamente para impedir o surgimento de tais conflitos, afastando-os da consciência.

12 No plano coletivo, os trabalhadores parecem organizados em diferentes clãs inimigos. A constituição de tais clãs tem por base o conflito de valores e de práticas profissionais acima referidas e opõe os trabalhadores que consideram a mentira um instrumento profissional legítimo, posto ao serviço de uma finalidade produtiva, aos teleoperadores que preferem concentrar-se num atendimento ao cliente desprovido de segundas intenções. A hostilidade entre os dois grupos assim constituídos é patente, cada qual acusando o outro de ser a origem das dificuldades vividas por todos. As recriminações, conflitos e embates são frequentes, podendo até dar lugar a confrontos violentos entre colegas. Segundo a psicodinâmica do trabalho, a focalização nos conflitos e acusaçães interpessoais permite evitar um debate construtivo sobre o trabalho real e as suas dificuldades. Este fenómeno coletivo é característico daquilo que denominamos ideologias defensivas, cuja função é precisamente impedir qualquer questionamento sobre as práticas profissionais em vigor.

13 Para além das estratégias acima referidas, é importante relatar um terceiro tipo de estratégias defensivas, deveras surpreendente. Trata-se daquilo que escolhemos apelidar de "estratégia defensiva da regressão infantil". Contrariamente às estratégias de defesa tradicionalmente estudadas em psicodinâmica do trabalho, desde sempre consideradas como criações originais e voluntárias dos trabalhadores, a estratégia da regressão infantil é promovida - e poderemos até dizer proposta - pela direção, sob a 
forma de jogos e concursos burlescos. Estes concursos ou challenges cumprem uma função claramente produtiva, sendo que o seu objetivo é promover a concorrência entre os operadores, cujo critério de avaliação passa pelo número de vendas realizadas. As equipes ou teleoperadores melhor classificados poderão então beneficiar de alguns minutos para jogarem com uma consola de videojogos ou pilotarem um helicóptero miniatura. As recompensas e prémios são regularmente deste tipo, remetendo os trabalhadores para aquilo que muitos interpretam como uma forma de infantilização. Aparentemente, os jogos profissionais incitam a condutas infantis e promovem uma forma de regressão ou imaturidade intelectual adotada por uma grande parte dos teleoperadores. A nosso ver, este tipo de comportamento contém uma vertente defensiva. A imaturidade intelectual à qual impelem os ditos jogos acompanha-se de uma renúncia à capacidade reflexiva, posta ao serviço das defesas. Ao abdicarem de um exercício pleno e independente do seu intelecto, os teleoperadores podem assim subtrair-se à reflexão sobre o carácter dúbio das suas práticas profissionais. Desta forma, a regressão infantil serve para desresponsabilizar todos e cada um das consequências do uso quotidiano da mentira, ou pelo menos para evitar qualquer interrogação sobre o assunto.

Este conjunto complexo de estratégias defensivas permite a uma parte dos trabalhadores manter o seu equilíbrio psíquico intacto, mediante uma dose de sofrimento penosa mas suportável. No entanto, este dispositivo informal desdobra-se em métodos de avaliação que fazem da capacidade de mentir com eficácia um dos critérios da qualidade do trabalho.

\section{Reconhecimento e avaliação do trabalho}

15 As recompensas e prémios de desempenho são invariavelmente atribuídos aos melhores vendedores do call-center, independentemente dos métodos utilizados para atingir tais performances. Aparentemente, aqueles que são considerados pelas chefias como sendo os melhores trabalhadores são também aqueles que manejam a mentira com mais subtileza e com menos escrúpulos. Ou seja, aqueles para quem a venda de novos produtos não implica forçosamente uma avaliação da natureza do pedido do cliente, nem das suas necessidades reais. Os melhores vendedores beneficiam igualmente de prémios e bónus comerciais que constituem uma parte importante do seu sálario e que os diferenciam dos demais colegas. As formas de remuneração e de reconhecimento do trabalho estão estreitamente relacionadas com critérios quantitativos, traduzidos essencialmente por indicadores numéricos (número de vendas, quantidade de telefonemas, etc.), mas sem qualquer apreciação de critérios qualitativos, tais como o respeito pelo pedido do cliente ou a sua satisfação com as respostas recebidas. Este sistema de avaliação do desempenho acarreta, logicamente, consequências práticas detalhadamente descritas na tese. Por um lado, estas incitações promovem implicitamente as vendas forçadas, os abusos comerciais e a propagação da mentira. Por outro lado, a instrumentalização do reconhecimento, aliada ao sofrimento ético e às defesas adotadas pelos trabalhadores, produz mecanismos de submissão pessoal tão inesperados quanto preocupantes.

16 Os elementos apresentados nesta tese sugerem uma necessidade de reavaliar os modelos atuais de organização do trabalho em centros de atendimento telefónico, isto se tivermos em conta a vivência subjetiva dos trabalhadores. A crítica formulada 
fundamenta-se essencialmente nos efeitos nefastos observados em termos de saúde no trabalho mas igualmente em considerações mais abrangentes relacionadas com a restrição da autonomia dos trabalhadores.

\title{
BIBLIOGRAFIA
}

Dejours, C. (1998). Souffrance en France. Paris, Seuil.

Dejours, C. (1980). Travail, usure mentale (Ed.2008, revista e ampliada). Paris, Bayard.

Dessors, D. (2009). De l'ergonomie à la psychodynamique du travail. Toulouse, Érès.

Ganem, V. (2011). Relato de uma experiência de terreno de intervenção em Psicodinâmica do Trabalho (PDT). Laboreal, 7, (1), 68-75. http://laboreal.up.pt/revista/artigo.php?

id=48u56oTV 6582235338949985532

Hughes, E.C. (2010). Les honnêtes gens et le sale boulot. Travailler, 24, 21-34.

Wisner, A. (1995). Réflexions sur l'ergonomie. Toulouse, Octarès.

\section{NOTAS}

1. O inquérito passa sempre pela constituição de pequenos grupos de trabalhadores, voluntários, para discutirem coletivamente a relação entre as dificuldades sentidas e os modos de organização do trabalho. Os grupos assim constituídos participam em sessões coletivas de reflexão de meiodia de duração. Cada grupo reúne-se entre 2 a 4 sessões. 0 material recolhido será depois reportado aos participantes sob a forma de um relatório escrito. Este relatório será discutido até ser validado pelos participantes e pelos intervenientes. Por fim, o relatório servirá de quadro de referência às discussões ulteriores visando a transformação da organização do trabalho. Os princípios metodológicos do inquérito em psicodinâmica do trabalho foram expostos de forma detalhada em Dejours (1980) e Dessors (2009).

\author{
AUTOR \\ DUARTE ROLO \\ Equipa de Psicodinâmica do Trabalho e da Ação, Conservatoire National des Arts et Métiers, 41 \\ rue Gay-Lussac, 75005 Paris, França \\ duarte.rolo@gmail.com
}

